\title{
PROMOTING INTERNATIONAL COLLABORATION THROUGH TRAINING AND EDUCATION IN SPACE TECHNOLOGY APPLICATIONS AND ADVANCES AMONG BIMSTEC COUNTRIES - A GOVERNMENT OF INDIA INITIATIVE
}

\author{
P.L.N. Raju ${ }^{1 *}$, Dibyajyoti Chutia ${ }^{1}$, Nilay Nishant ${ }^{1}$, Jonali Goswami ${ }^{1}$, Ritu Anil Kumar ${ }^{1}$ \\ ${ }^{\mathbf{1}}$ North Eastern Space Applications Centre, Umiam, Shillong, Meghalaya, India \\ (plnraju@gmail.com, d.chutia@nesac.gov.in,nilaynishant@gmail.com,jonali.goswami@gmail.com, ritu.anilkumar@gmail.com)
}

Commission V, WG V/2

KEY WORDS: Space Technology Applications, BIMSTEC, International Cooperation, training, capacity building

\begin{abstract}
India is one of the top space-faring nations in the world, which not only to build satellites and launches them using indigenously developed launch vehicles but also spearheads the use of space technology for many applications at the national and international level. Training, education and capacity building (TECB) are important components in promoting the use of space technology, thereby benefitting the society. North Eastern Space Applications Centre (NESAC) is one of many institutions under the umbrella of Indian Space Research Organisation (ISRO), Department of Space (DOS) which is responsible for promoting TECB at National level. ISRO / DOS also supports TECB at an International level through many initiatives such as IIRS - ITC JEP, UN-CSSTEAP, CEOS, UNSPIDER, UN-FAO, WMO, Commonwealth, and BIMSTEC etc. NESAC established in 2000, initiated capacity building and spearheaded Outreach programs from 2019 in the North East Region of India. Prime Minister of India announced in the plenary meeting of BIMSTEC(Bay of Bengal Initiative for Multi-Sectoral Technical and Economic Cooperation) Summit at Kathmandu, Nepal in August 2018, recognizing NESAC to conduct space technology training programs of two weeks and 3 months for BIMSTEC Countries every year for the next five years with full financial support from Government of India. The first two week training program on "capacity building on the earth observation applications and research" was successfully conducted for 24 participants, four participants each representing Bangladesh, Bhutan, Thailand, Myanmar, Nepal, and Sri Lanka. The participants are from User Departments, Science and Technology Ministries, Space Organizations and Academia and Research Institutions. The training benefitted the participants from state of the art training facilities and experienced faculties from NESAC/ISRO/Academia from across India. The summary of feedback from the participants (excellent $-57 \%$, good $-40 \%$, average $-2.6 \%$ and poor $-0.4 \%$ ) indicates that the course is very much useful as it has enhanced their knowledge in earth observation, geospatial analysis capabilities that will be put into use on their return. The training and capacity building has opened new vistas of cooperation and possible collaboration between BIMSTEC countries ranging from availing satellite data, expansion and access to data sharing portals, creating knowledge network to promote young researchers and expert sharing within the region, further to expand the capacity building by initiating distance learning programs, taking up joint research and application projects, etc. The rich experience of conducting a unique program, one of its kind and detailed feedback and possible expansion of BIMSTEC programs in the future is presented in the paper.
\end{abstract}

\section{INTRODUCTION}

India has large a number of remote sensing satellite constellation, supporting and spearheading various applications operationally at the national level. Forestry, environment, agriculture, geology, water resources, urban, coastal zone, marine resources, snow and glaciers, disaster monitoring and mitigation, infrastructure development etc. which are the major applications made operational (Navalgund, et al., 2007) utilising Indian remote sensing / other satellite data. NESAC is responsible to carry out the operational projects for the North Eastern region. Additionally, NESAC is mandated to provide application services like natural resource management, space and atmospheric sciences, satellite communication for teleeducation, disaster risk reduction, governance and development since its inception in 2000 (Raju et al., 2016). ISRO/DOS is promoting space technology services through training, education, research and capacity building at national / international level through its important institutions established across the country such as Indian Institute of Remote Sensing (IIRS, www.iirs.gov.in), National Remote Sensing Centre (NRSC, www.nrsc.gov.in), Indian Institute of Space Science and Technology (IIST, https://www.iist.ac.in/), and NESAC (www.nesac.gov.in). The Indian government, through Ministry of External Affairs (MEA) and Indian Space Research Organisation (ISRO, https://www.isro.gov.in/); support several international initiatives like ITEC (International Technical Economical Cooperation), BIMSTEC, IIRS - ITC (International Institute for Geo-Information Science and Earth Observation) - JEP (Joint Education Programme), UNCSSTEAP (Centre for Space Science and Technology for Asia Pacific), CEOS (Committee on Earth Observation Satellites), UN-SPIDER (Space-based Information for Disaster Management and Emergency Response), UN-FAO, WMO, Commonwealth, etc. and promoting training, education, capacity building and international collaboration.

IIRS played important role in initiating and expanding geoinformatics training, education and research (Raju et al. 2007) at India level and as well as at International level through Joint Education program in collaboration with ITC (Raju and Dadhwal 2010). In addition, IIRS further expanded the scope of training to reach the large number who will not be able to attend the training programs in person, by initiating live distance learning and e-learning programs (through an online platform) to reach the unreached (Murthy et al. 2014). Geoinformatics Centre (GIC), a self funded outreach centre of Asian Institute of technology (AIT) was established in the year 1995 with the

* Corresponding Author 
financial collaboration of United Nation Environment Program of Asia and Pacific. In Asian region, National Space Development Agency (NASDA) of Japan has supported GIC in providing funds, satellite data and contributed to capacity building in remote sensing and related space technologies (Samarakoon et. al.2008).

\section{BIMSTEC Training Programs at NESAC}

NESAC is recognised by the MEA, Government of India and ISRO to conduct training and Capacity Building Programs for BIMSEC countries. BIMSTEC was formed by some geographically contiguous South Asian and ASEAN countries in the Bay of Bengal region. Main ideas behind this sub regional grouping by the member countries are to leverage the synergies in their capabilities and resource endowments for their development. The member countries Bangladesh, Bhutan, India, Myanmar, Nepal, Sri Lanka and Thailand, complementing economies that provide a strong fertile ground for cooperation as each member country possesses unique capabilities in varied areas, which could be a source of sharing and learning among members of the group (https://bimstec.org/). During the Fourth Summit of BIMSTEC held at Nepal capital Kathmandu on 30th and 31th August 2018 , honourable Prime Minister of India emphasized the connectivity and greater cooperation and coordination among member states. In accordance to this, the honourable Prime Minister of India declared that the Government of India will provide outreach and capacity building programme to the researchers, students and professors of BIMSTEC countries on Space Technology Tools and Applications, to be conducted at NESAC as given below:-

- Short Term Residential Course: 12 Research Personnel (2 candidates from each BIMSTEC country) on the Fundamentals of Remote Sensing and GIS. Every year two similar courses are planned for 24 persons. Three Month Residential Certification Course: 12 Research Personnel (2 candidates from each BIMSTEC country) will attend the course. Two such courses are planned every year for 24 persons.

Both the courses are planned for a period of 5 years. The MEA, to start with, suggested that the BIMSTEC \& SAARC Division conduct onetime two weeks course for the 24 BIMSTEC participants during the period 2019-2020 instead of two times similar courses with 12 participants in each course. Future training may be planned based on the feedback.

\section{ACHIEVMENTS - BRIEF SUMMARY}

NESAC successfully conducted the first 2-week training on Capacity Building on the Earth Observation Applications and Research: fundamentals, emerging technological tools and services for the BIMSTEC Countries during January 06-17, 2020. A total of 24 participations from various User Departments, Science and Technology Ministries, Space Organizations and Academia and Research Institutions of BIMSTEC countries attended the course. The training was imparted with the objective to strengthen the capacity of Earth Observation Applications and Research through customized training courses on Remote Sensing and GIS and emerging technological tools and services. The training has been designed to provide an opportunity for the participants to learn various aspects of Space Technology and relevant geospatial applications enhancing their ability and enable them to take up various applications in their respective countries after returning back to their country.

\subsection{Course structure and mode of training}

The content of programme includes the topics ranging from the fundamentals of remote sensing, Geographical Information System (GIS), image processing, GNSS (Global Navigation Satellite System) and applications, photogrammetry, emerging technological tools and applications like unmanned aerial vehicle (UAV) remote sensing, machine learning and specific application-oriented lectures. The lectures were a balanced mix of theoretical and practical classes, including mini pilot project work. The contents comprised of total nine modules, prepared based on the real-world applications (Table 1). The total working hours (hrs) for entire two weeks course was 90 where more than $60 \%$ of the time was spent for hands-on training in the form of practical, project assignments, field visits and implementation of mini projects etc. The core resource personnel were selected considering their expertise as well as experience in teaching. They were mostly from NESAC and other experts from premier institutions of India, invited to cover a few topics and to share their experiences.

All the theoretical cum hands-on classes were conducted in a smart class room equipped with cloud computing facility networked with very-high speed internet connectivity. At the end of the theory classes, participants were exposed to free and open source software (FOSS) for digital image processing and GIS. Major focus was given to make the environment more interactive, learning and live by conducting online quiz competitions after the theory classes. This made the participants more attentive and motivated throughout the whole training courses. The training material like lecture notes, presentation slides etc. as well as the training datasets were shared with the participants at the end of each day for submission of work assignments.

In addition to regular lecture and hands-on series, two field trips were organized for the benefit of the participants in their course structure. The first field trip was carried out nearby NESAC, in the beginning of the course for better understanding of satellite image interpretation (Figure 1(a)). The visual interpretation on the land use features of Umiam Lake and its surroundings by referring the corresponding hardcopy of remote sensing images was quite interesting and effective for the participants. The second field survey was planned in the mid of course after the GPS/GNSS theory classes, for understanding the operation of GPS and GAGAN devices for planning various kinds of location based services (LBS). This was a whole day programme and the participants were taken to Cherrapunjee, Meghalaya which has recorded the highest rainfall globally, for understanding the operation of GPS (Global Positioning System) and GAGAN (GPS Aided Geo-Augmented Navigation) devices for planning various kinds of location based services (LBS). 


\begin{tabular}{|c|c|c|c|c|}
\hline $\begin{array}{l}\text { Sl. } \\
\text { No. }\end{array}$ & Modules & $\begin{array}{c}\text { Lectures } \\
\text { (hrs) }\end{array}$ & $\begin{array}{c}\text { Hands-On } \\
\text { (hrs) }\end{array}$ & $\begin{array}{c}\text { Project } \\
(\mathrm{hrs})\end{array}$ \\
\hline 1 & Remote Sensing /Earth Observation & 2.5 & 4 & 1 \\
\hline 2 & Digital Image Processing & 5 & 8 & 1 \\
\hline 3 & Geographic Information System & 6 & 9 & 2 \\
\hline 4 & GPS Series & 3 & 4 & 1 \\
\hline 5 & $\begin{array}{l}\text { Basics of Photogrammetry and UAV Remote } \\
\text { Sensing }\end{array}$ & 3 & 4 & 1 \\
\hline 6 & Emerging Technology and Recent Trends & 3 & 4 & 1 \\
\hline 7 & $\begin{array}{l}\text { Potential Application Domain using Geospatial } \\
\text { Technology }\end{array}$ & 3 & 4 & 1 \\
\hline & Sub total & 25.5 & 37 & 8 \\
\hline 8 & Field Visit & \multicolumn{3}{|c|}{11.5} \\
\hline 9 & Implementation of mini project \& demonstration & \multicolumn{3}{|c|}{8} \\
\hline & Total & \multicolumn{3}{|c|}{90} \\
\hline
\end{tabular}

Table 1. Module-wise allocation of time (hrs) for lecture/hands-on series etc.
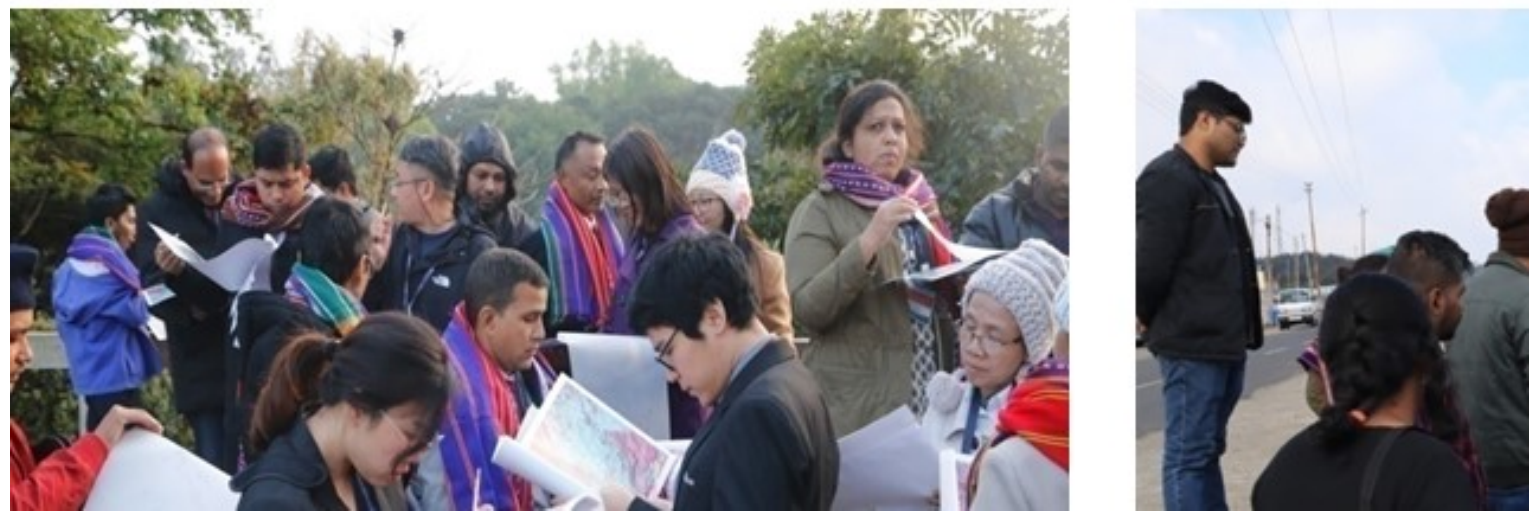

Figure 1. a) Understanding the interpretation of satellite data at Umiam lake, Meghalaya and

b) Understanding the working principle of GPS and GAGAN at Cherrapunjee (i.e. locally known as Sohra), Meghalaya

\subsection{Implementation of mini projects}

The participants were also required to carry out mini project as part of their training course. The projects were distributed across three broad domains: a) natural resources management, b) disaster management support and c) urban and infrastructure planning. The purpose of mini project was to enable the participants to understand the potential of the space technology tools and applications in the implementation of real world problems specific to BIMSTEC countries and also practically put into use that the knowledge they gained through the training program. The FOSS software like QGIS/GDAL on GIS and digital image processing and Google earth engine (GEE) with Python libraries on machine learning has been appropriately utilized during implementation of mini projects. Total of six important project themes were considered based on the discussion with the participants. Each project theme was assigned to four participants considering their choices as well as the thematic background. Each project team was mentored by two experienced resource persons from NESAC. The mini projects with study area and the source of data is listed in the
Table 2. Some of the interesting results and findings are depicted in the figures (i.e. Figure 2, Figure 3 and Figure 4).

\subsection{Potential collaborations arising from the Course}

The participants are of the view that all the BISMSTEC countries need to collaborate utilising potential of specific institute / country. Several potential domains of collaboration were discussed and identified during the training programme. They are:

- Availability of high resolution Indian satellite data and Access of data sharing portals among BIMSTEC countries for carrying out research and developmental activities.

- Expanded the training in the form of distance learning programs and deputation of resource persons.

- Tailor made oriented capacity building programs in specific application areas.

- Exchange programs and short term courses to ensure opportunities for students and young researchers of BIMSTEC countries. 


\begin{tabular}{|c|l|l|l|}
\hline $\begin{array}{c}\text { Sl. } \\
\text { No. }\end{array}$ & \multicolumn{1}{|c|}{ Project themes } & \multicolumn{1}{c|}{ Study area } & \multicolumn{1}{c|}{ Data sources } \\
\hline 1 & $\begin{array}{l}\text { Site suitability analysis for tentative afforestation } \\
\text { zones in the Deepor Beel region }\end{array}$ & $\begin{array}{l}\text { Deepor Beel region, Assam, } \\
\text { India }\end{array}$ & LISS III, Landsat \\
\hline 2 & Hydrological Modelling for the Ranganadi Basin & $\begin{array}{l}\text { Ranganadi Basin, Assam, } \\
\text { India }\end{array}$ & LISS-IV, SRTM DEM \\
\hline 3 & $\begin{array}{l}\text { Crop Damage assessment for the nation of } \\
\text { Bangladesh using MODIS flood data }\end{array}$ & Bangladesh & MODIS, Sentinel 2 \\
\hline 4 & Crop Acreage Estimation using Satellite Imagery & Part of Bhutan and Sri Lanka & Sentinel 2 \\
\hline 5 & $\begin{array}{l}\text { Spatial distribution of seismic events on the Nepal } \\
\text { Himalayas from 1900 to 2019 }\end{array}$ & Nepal Himalayas & MODIS \\
\hline 6 & Urban Heat Island Analysis & Kathmandu, Nepal & Landsat, MODIS \\
\hline
\end{tabular}

Table 2. List of mini projects with study area and sources of data
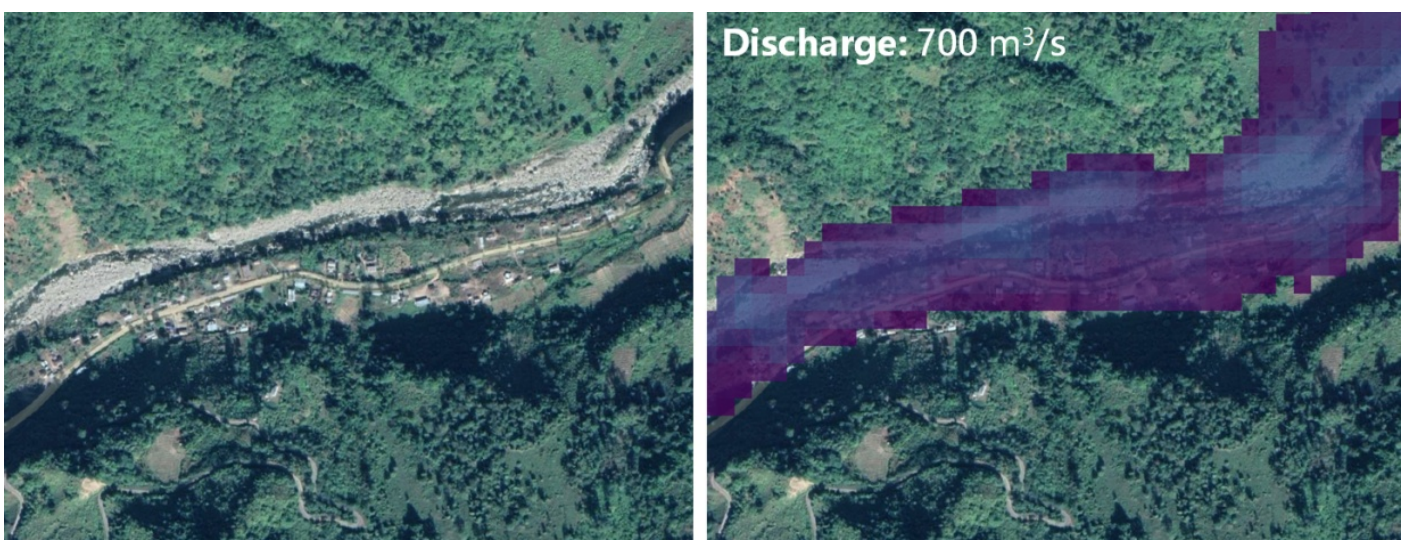

Figure 2. Hydrologic and hydraulic model for river flood forecasting for the Ranganadi Basin, Arunachal Pradesh

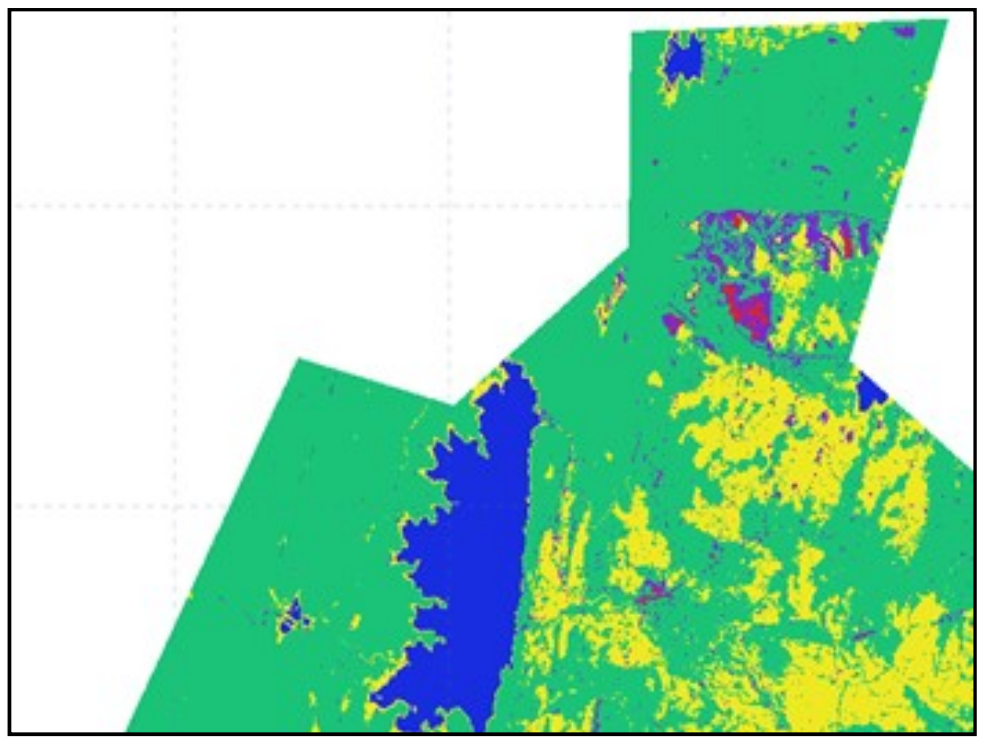

Figure 3.Agricultural Acerage Estimation, Sri Lanka 


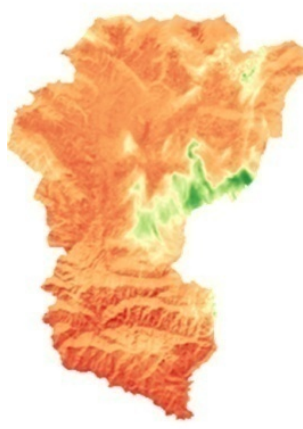

Land surface temperature 2019

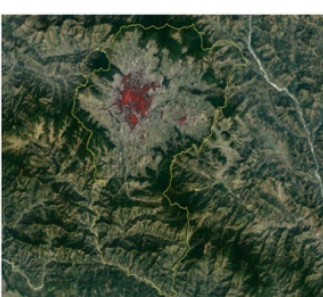

Landsat 52004

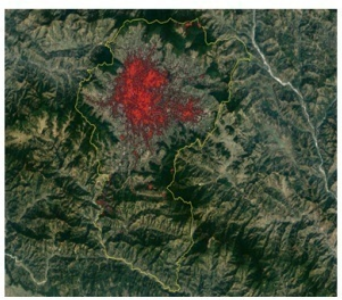

Landsat 82019

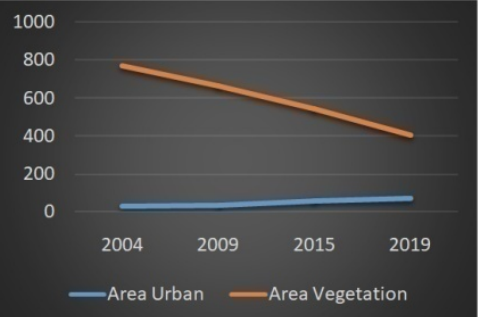

Urban Expansion

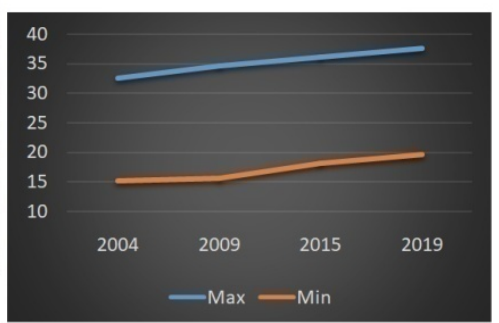

Temperature Change

Figure 4. Relationship between Urban Growth and Land Surface Temperature for Kathmandu, Nepal

Some of the major recommendations, taking into account of the participant feedback and future plans for the benefit BIMSTEC countries are highlighted below:

- Creating a structured knowledge network to promote young researchers and allow expertise sharing within the region in the form of ingenious journals and international conferences.

- Potential collaboration to set up test sites for calibration of THEOS satellite over expansive land covers of Snow/Ice in Sikkim, water bodies and sand bed in Brahmaputra etc.

- Potential collaborations with space-based startups in India for indigenous instrument development.

- Crop Production estimation techniques for NER are similar to the hilly regions of Bhutan and expansion of results for North East can be done to Bhutan as well.

- Microclimate modelling to assess the impact of climate change and urbanization.

\subsection{Evaluation of the training course}

Several components of the program were considered to evaluate the efficacy and quality of the course. Instant online feedback tools were used just after the lectures and lab exercises to understand the difficulty of the participants in interpreting the lecture series. It helped the resource persons to re-organize their presentation material / lecture notes to give more clarity on their talks. The summary of the feedback from the participants indicates that the course is very much useful as it has enhanced their knowledge in earth observation, geospatial analysis capabilities that will be put into use on their return. The rating of the participants on different parameters of feedbacks is depicted in the Figure 5. It was quite encouraging and $90 \%$ of the participants have rated the overall course as 'Excellent' and the remaining $10 \%$ have rated for 'Very good'. Some of the important suggestions of the participants are highlighted below:

- The duration of the training course should be extended with longer duration courses.

- It would be interesting if the participants could be placed under the guidance of a mentor who is perhaps relevant to the participant's background in implementing the mini project in selected areas of specific interest.

- To include more case study examples as part of lectures / practical for better understanding and use.

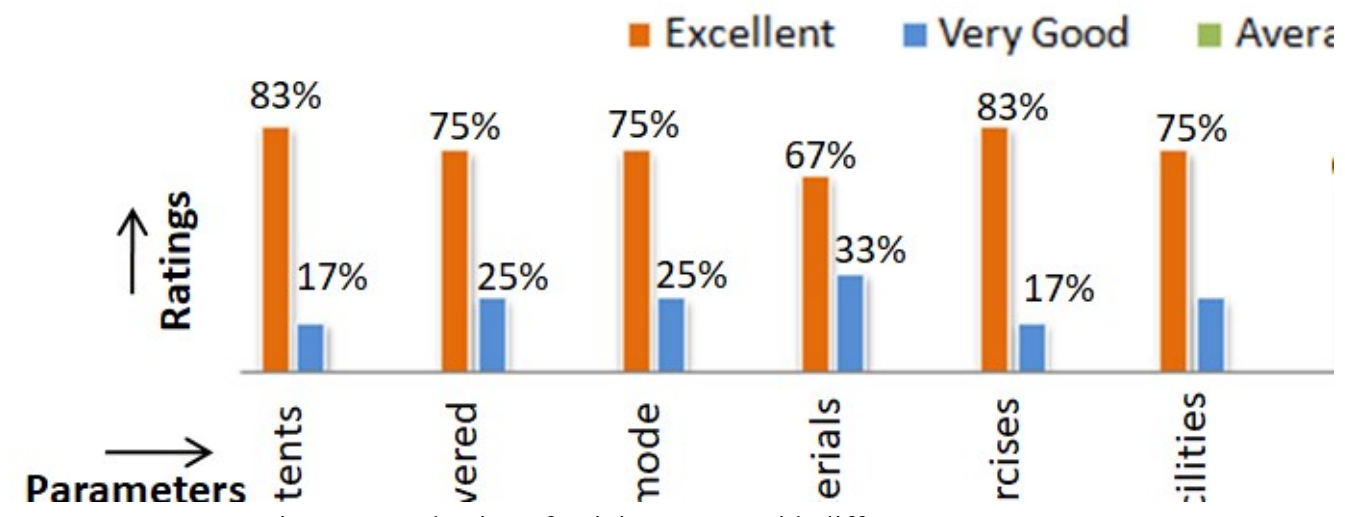

Figure 5: Evaluation of training course with different parameters 


\section{CONCLUSIONS AND RECOMMENDATIONS}

It was an opportunity and also an honour for NESAC to showcase its potential to conduct an international training program to BIMSTEC countries for the first time. It is a one of its kind programs, conducted to the satisfaction of the participants. ISRO/DOS is in the forefront in conducting the international TECB programs under different institutions or sponsored programs like: IIRS, CSSTEAP (UN Centre), ITEC, UNOOSA, FAO, WMO, Commonwealth, UN ESCAP etc. The training that just concluded at NESAC is the new program and it will be continued for the next four years, as committed by Ministry of External Affairs, Government of India. The overall feedback of the training program is very much satisfactory and it will be further improved in the coming years taking the feedback into consideration and conduct it better. The training program has enabled international collaboration among BIMSTEC countries with possible collaborations and recommendations as listed in the following:

- The first recommendation is to continue the program for the next four years, as committed by government of India.

- Sharing of expert knowledge

- Enabling the availability of satellite data among BIMSTEC countries

- In addition to two weeks of training, the long duration certificate program of three months duration will be initiated and conducted in the next four years period.

- The beginning of the BIMSTEC training programs at NESAC has opened new vistas to expand collaboration among the user departments / research institutions.

- Proximally located, facing similar challenges due to continuous topographic and geographic conditions gives the north eastern region of India a unique advantage when working with the BIMSTEC countries. Further, NESAC with its rich working experience for the last two decades in the domain of space technology is the most appropriate choice in line with the government's Look East policies to conduct the training programs for BIMSTEC countries.

- It is also possible to expand the international collaboration beyond the BIMSTEC countries, if given the opportunity to NESAC.

\section{ACKNOWLEDGMENT}

This program was feasible only due to the vision of honourable Prime Minister of India Shri Narendra Modi. NESAC acknowledge Ministry of External Affairs, Govt of India for sponsoring and guiding NESAC in organizing this program. NESAC also acknowledge Ministry of DoNER, Government of India and North Eastern Council (NEC), for their directive and suggestions in preparing the proposal for conducting this programme to the BIMSTEC countries professionals. We also express our gratitude to Chairman, NESAC GC/ISRO and Secretary, DOS for according approvals and providing the start of the infrastructure facility.

\section{REFERENCES}

Navalgund, R.R., Jayaraman, V., Roy, P.S., 2007. Remote Sensing Applications: An overview., Current Science, pp. 17471766, 93(12), 25 DECEMBER 2007.

Raju, P.L.N., Sarma, K.K., Barman, D., Handique, B.K., Chutia, D., Kundu, S.S., Das, K.D., Chakraborty , K., Das, R.,
Goswami, J., Das, P., Devi, H.S., Nongkynrih, J.M., Bhusan, K., Singh, M.S., Singh, P.S., Saikhom, V., Goswami, C., Pebam, R., Borgohain, A., Gogoi, R.B., Singh, N.R., Bharali, A., Sarma, D., Lyngdoh, R.B., Mandal, P.P., Chabukdhara, M., 2016. Operational Remote Sensing Services in North Eastern Region of India for Natural Resources Management, Early Warning for Disaster Risk Reduction and dissemination of information and services, The International Archives of the ISPRS, XLI-B4, 2016 XXIII ISPRS Congress, 12-19 July 2016, Prague.

Raju, P.L.N., Dadhwal, V.K., Jeganathan, C., 2007. GIS Education and Training at Indian Institute of Remote Sensing.GIS Development Asia Pacific, March 11(3).

Raju, P.L.N., Dadhwal, V.K., 2010. IIRS Perspective on Lessons from Implementation of a Cross Border Joint Education Program. ISPRS Archives - Volume XXXVIII Part 6, 2011, pp. 102-106.

Samarakoon, L., Hazarika, M.K., Inomata, Y., 2008. Effective approach for Capacity Building in GIS and Remote Sensing technologies in developing countries. The International Archives of the Photogrammetry, Remote Sensing and Spatial Information Sciences, Commission VI, WG VI/6, Vol. XXXVII, pp 201-206

Murthy, Y.V.N.K., Raju, P.L.N., Srivastav,S. K., Karnatak, H., Gupta, P.K., Mahadevaswamy,M., Viswakarma, J., 2014. Reach the Unreached-IIRS Outreach program for enhanced learning to all. The International Archives of the Photogrammetry, Remote Sensing and Spatial Information Science, XL-8, 1243-1247, 2014, www.int-arch-photogrammremote-sens-spatial-inf-sci.net/XL-8/1243/2014/doi:

10.5194/isprsarchives-XL-8-1243-2014. 